\title{
COLOUR VISION IN DIABETIC AND NORMAL PSEUDOPHAKES IS WORSE THAN EXPECTED
}

\author{
P. J. KNOWLES, S. J. TREGEAR, L. G. RIPLEY and A. G. CASSWELL \\ Brighton
}

\begin{abstract}
SUMMARY
Automated colour vision testing in pseudophakes showed unexpected results. Chromatic discrimination sensitivity was measured in 22 diabetic pseudophakes with no retinopathy, 23 diabetic pseudophakes with background retinopathy and 34 non-diabetic pseudophakes. These results were compared with those in agematched normal and diabetic phakic subjects, all of whom had good vision. The diabetics were also matched for retinopathy grading and duration of diabetes. In all three groups, red-green discrimination sensitivity was worse in the pseudophakes when compared with the corresponding phakic subjects (normals, $p<0.001$; no retinopathy, $p=0.467$; background retinopathy, $p=0.057$ ). However, tritan vision was marginally worse in the normal pseudophake group but was better in the two diabetic pseudophake groups, when compared with phakic controls. This may be due to a reduction in tritan sensitivity in age-matched phakic controls from the effects of increased lens yellowing with age.
\end{abstract}

Colour vision testing provides a sensitive, noninvasive method by which to measure damage to the retina. Deterioration in colour vision often precedes changes in other clinical measures such as visual acuity. Many investigators have studied colour vision in diabetic patients and have found that both red-green and tritan colour deficits are seen, tritan losses being most severe. ${ }^{1-7}$ Investigators have also shown that tritan vision deteriorates with age in nondiabetic and diabetic populations ${ }^{8,9}$ and with duration of diabetes. ${ }^{10,11}$ It has been suggested that the tritan-type deficit seen in diabetes is partly due to the blue cone system being more susceptible to retinal damage than the red or green cone systems. It is thought that age and duration changes in tritan vision may be due to lens yellowing, and to an increased rate of lens yellowing in diabetes. ${ }^{12} \mathrm{We}$ thought it

Corrrespondence to: Mr A. G. Casswell, FRCS, FRCOphth, Sussex Eye Hospital, Eastern Road, Brighton, East Sussex BN2 $5 \mathrm{BF}, \mathrm{UK}$. would be interesting to compare colour vision of both diabetic and non-diabetic subjects who had had cataract surgery with age-matched phakic controls in the hope that this may shed some light on the effects of lens yellowing.

\section{SUBJECTS AND METHODS}

Chromatic discrimination sensitivity was measured in 22 diabetic pseudophakes with no retinopathy, 23 diabetic pseudophakes with background retinopathy and 34 normal (not diabetic) pseudophakes. All subjects had had extracapsular cataract surgery or phacoemulsification with posterior chamber implants. Patients were examined at least 3 months after cataract surgery. Subjects and controls were excluded if their visual acuity was less than $6 / 12$, if they had had previous laser treatment, or if they had any other eye disease likely to affect their colour vision, such as glaucoma or macular degeneration. Controls were excluded if they had significant cataract.

Chromatic discrimination sensitivity was measured using a computer-controlled cathode ray tube (CRT)-based system. ${ }^{10,11,13}$ The system produces equiluminant, sinusoidal, low spatial frequency, chromatic gratings of variable saturation. Chromaticity is changed around the neutral white point along the red-green (constant s cone system) and the tritan (constant $\mathrm{m} / \mathrm{l}$ cone system) axis. The point at which the observer can just perceive coloured bands on a neutral background is determined using a doublestaircase reversal algorithm. ${ }^{14}$

Subjects' pupils were then dilated. Those who had observable posterior capsular opacity were excluded from the study, because we have found that posterior capsular changes can affect contrast sensitivity results. In diabetic patients the fundi were then examined using a $78 \mathrm{D}$ lens and slit lamp to assess the degree of diabetic retinopathy. Retinopathy was graded into no diabetic retinopathy (no abnormalities at all) and background retinopathy 
Table I. Colour vision in normal (non-diabetic) subjects

\begin{tabular}{lcccc}
\hline & Phakic controls & Pseudophakes & $t$-test $p$ value $^{a}$ & Mann-Whitney $p$ value $^{b}$ \\
Sample size & 34 & 34 & & $<0.001$ \\
Mean red-green & 0.520 & 0.664 & & 0.089 \\
Mean tritan & 0.619 & 0.679 & 0.914 & \\
Mean age (years) & 74.1 & 74.3 & & \\
\hline
\end{tabular}

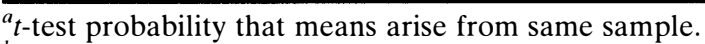

${ }^{b}$ Mann-Whitney test probability that means arise from same sample.

Table II. Colour vision in diabetics with no retinopathy

\begin{tabular}{lcccc}
\hline & Phakic controls & Pseudophakes & $t$-test $p$ value $^{a}$ & Mann-Whitney $p$ value $^{b}$ \\
\hline Sample size & 22 & 22 & & 0.467 \\
Mean red-green & 0.537 & 0.610 & & 0.119 \\
Mean tritan & 0.786 & 0.660 & 0.554 & \\
Mean age (years) & 74.2 & 75.5 & \\
\hline
\end{tabular}

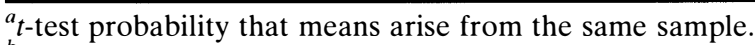

${ }^{b}$ Mann-Whitney test probability that means arise from the same sample.

(microaneurysms, dot and blot haemorrhages and hard exudates). Patients with maculopathy (significant macular oedema), pre-proliferative retinopathy (cotton wool spots, venous changes and multiple intraretinal microvascular abnormalities) and proliferative retinopathy (disc and peripheral new vessels) were not included in the study as the numbers were too small to give meaningful results.

The chromatic discrimination sensitivity results were compared with those of age-matched normal and diabetic phakic subjects. The diabetics were also matched for retinopathy grading and, as far as possible, for duration of diabetes.

The results were analysed using the non-parametric Mann-Whitney $U$-test based on ranking of sensitivities. The age groups were compared using Student's $t$-test.

\section{RESULTS}

In all three groups red-green discrimination sensitivity was worse in pseudophakes when compared with the corresponding phakic subjects (Tables I-III, Fig. 1). The difference was statistically significant only in the normal subjects. Tritan discrimination sensitivity was worse only in the non-diabetic pseudophake group (Fig. 2). The tritan discrimination sensitivity in the two diabetic pseudophake groups was better than in the phakic controls.

When colour vision was compared between diabetic pseudophakes with no retinopathy and those with background retinopathy both red-green and tritan vision were found to be worse in the group with background retinopathy, although the difference was significant only for red-green vision (Table IV). This difference is more noticeable in view of the fact that the subjects with background retinopathy were significantly younger.

\section{DISCUSSION}

In all the groups studied red-green discrimination was worse in the subjects who had had cataract surgery. Tritan discrimination was better in the two diabetic pseudophake groups and worse in the nondiabetic pseudophake group than in phakic controls. It is thought that diabetics have an increased rate of lens yellowing. ${ }^{11}$ It may be that lens yellowing in the phakic subjects reduces tritan sensitivity leading to apparently better tritan sensitivity in pseudophakes, despite a possible overall decrease in chromatic discrimination sensitivity in pseudophakes.

Table III. Colour vision in diabetics with background retinopathy

\begin{tabular}{|c|c|c|c|c|}
\hline & Phakic controls & Pseudophakes & $t$-test $p$ value $^{a}$ & Mann-Whitney $p$ value ${ }^{b}$ \\
\hline Sample size & 23 & 23 & & \\
\hline Mean red-green & 0.601 & 0.789 & & 0.057 \\
\hline Mean tritan & 0.823 & 0.806 & & 0.652 \\
\hline Mean age (years) & 67.3 & 69.2 & 0.655 & \\
\hline
\end{tabular}

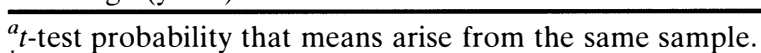

${ }^{b}$ Mann-Whitney test probability that means arise from the same sample.

Table IV. Comparison between diabetic pseudophakes with no retinopathy and background retinopathy

\begin{tabular}{lcccc}
\hline & No retinopathy & Background retinopathy & $t$-test $p$ value $^{a}$ & Mann-Whitney $p$ value $^{b}$ \\
\hline Sample size & 22 & 23 & & 0.035 \\
Mean red-green & 0.610 & 0.789 & & 0.307 \\
Mean tritan & 0.660 & 0.806 & 0.093 & \\
Mean age (years) & 75.5 & 73.0 & \\
\hline
\end{tabular}

${ }^{a} t$-test probability that means arise from the same sample.

${ }^{b}$ Mann-Whitney test probability that means arise from the same sample. 


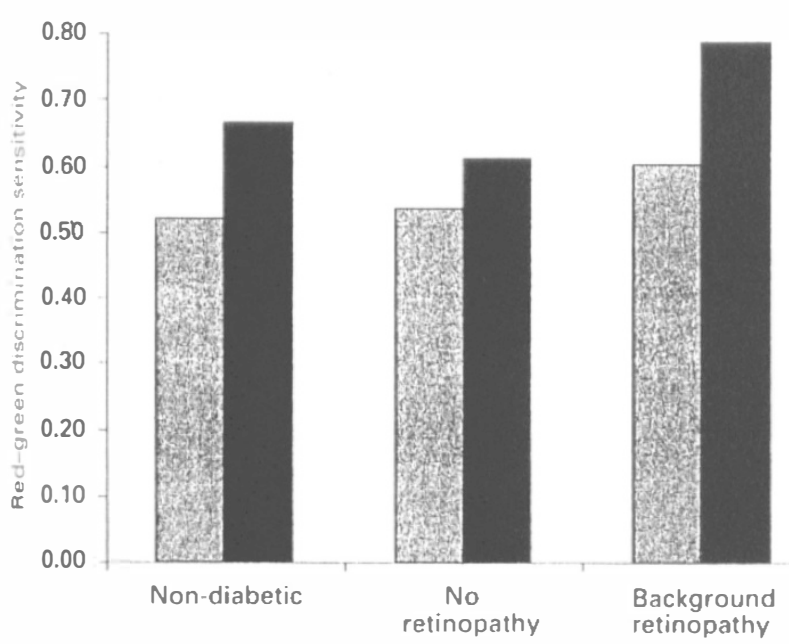

Fig. 1. Red-green discrimination sensitivity in phakic controls (grey columns) and pseudophakes (black columns).

In our study we excluded patients with visual acuities of less than $6 / 12$ and those with posterior capsule opacities as seen on the slit lamp. Studies have shown that posterior capsular opacification can cause glare and can reduce the visual acuity under glare conditions in the presence of a normal visual acuity under standard conditions. ${ }^{15,16}$ We have found that posterior capsular opacities reduce both achromatic and chromatic discrimination sensitivity.

One cause for poorer colour vision following cataract surgery may be increased short-wavelength light transmission through intraocular lenses causing photochemical retinal damage. In the phakic subject the normal crystalline lens protects the retina by absorbing short-wavelength visible and ultraviolet light. The crystalline lens absorbs most light of a wavelength below $400 \mathrm{~nm}$ and much of the shorterwavelength visible radiation. Polymethylmethacrylate intraocular lenses transmit more short-wavelength light than the crystalline lens. ${ }^{17}$ The pseudophakic eye was 4 times more sensitive than the average phakic eye to spectral light between 380 and $450 \mathrm{~nm}$. During the period of this study many of the patients had an Intra Optics intraocular lens, which the manufacturer claims absorbs $90 \%$ of light below $406 \mathrm{~nm}$.

Another possible cause for reduced colour vision following cataract surgery could be cystoid macular oedema (CMO). CMO is an accumulation of extracellular fluid, usually in the outer plexiform layer. Its persistence will result in retinal tissue breakdown and loss of visual function. Pollack et al. ${ }^{18}$ performed fluorescein angiography at 6 weeks and found a $50 \%$ incidence of subclinical CMO in diabetics, and an $8 \%$ incidence in their non-diabetic control group. They also found a higher incidence of $\mathrm{CMO}$ in those diabetics who had pre-existing retinopathy before surgery. Menchini et al. ${ }^{19}$ looked at angiographic $\mathrm{CMO}$ in diabetics with no retino-

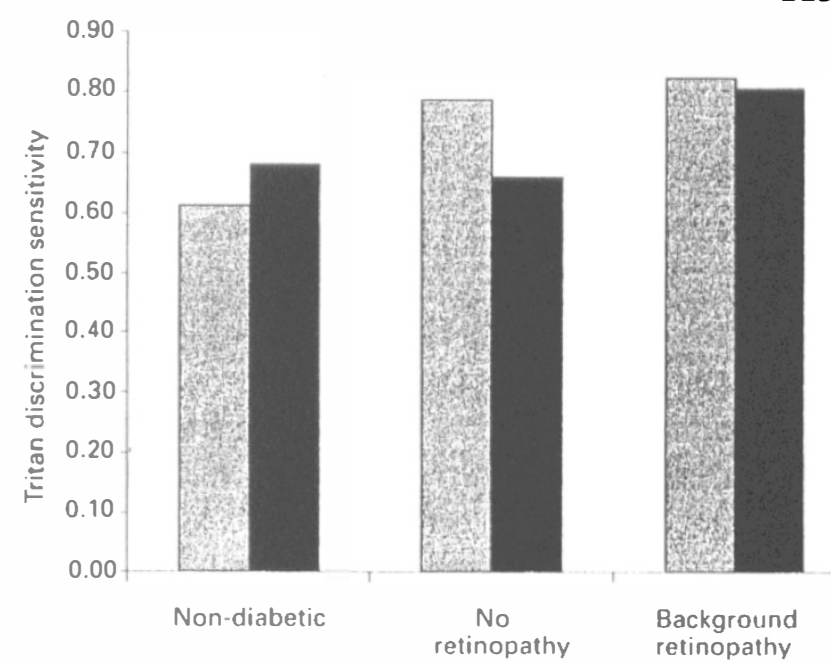

Fig. 2. Tritan discrimination sensitivity in phakic controls (grey columns) and pseudophakes (black columns).

pathy and normals, and found an incidence of $68.8 \%$ in diabetics and $62.5 \%$ in normals.

Jampol et al. ${ }^{20}$ studied 297 patients to determine the effect of a UV-blocking filter on the operating microscope on the angiographic incidence of CMO in patients undergoing extracapsular cataract surgery with a posterior chamber lens. They found an incidence of post-operative CMO in patients without the filter of $21 \%$, compared with $7.3 \%$ in the group with a filter. This difference was not significant.

In our study we found that colour vision in diabetic pseudophakes was worse in those with background retinopathy than in those with no retinopathy, although the difference was significant only for red-green discrimination. Many studies have looked at the effects of cataract surgery on diabetic retinopathy, and have found that patients with more advanced stages of diabetic retinopathy do worse following cataract surgery. ${ }^{20-24} \mathrm{~A}$ meta-analysis by Dowler et al. ${ }^{24}$ showed that $87 \%$ of diabetics with no retinopathy achieved a visual acuity of $6 / 12$ or better. This figure was reduced to $80 \%$ in the presence of background retinopathy, and to $57 \%$ or less in the presence of proliferative changes or maculopathy.

Tritan discrimination sensitivity measurements have been proposed as a method of screening for serious retinopathy. Our results show that tritan discrimination is worse in diabetic pseudophakes with background retinopathy than in those with no retinopathy. There were not enough diabetic pseudophakes with maculopathy and proliferative retinopathy to examine the effects of these conditions on tritan sensitivity.

Tritan vision was better or only slightly worse in pseudophakes when compared with phakic controls. This supports the theory that tritan sensitivity is reduced with age and diabetic duration because of lens yellowing. 
The reason for reduced colour vision in normal and diabetic pseudophakes is not clear. It may be due to retinal damage by short-wavelength light (either from the operating microscope or post-operatively), or cystoid macular oedema. In phacoemulsification there is a shorter period when the retina is exposed to the light from the operating microscope after removal of the crystalline lens.

Key words: Cataract extraction, Colour vision, Diabetic retinopathy.

\section{REFERENCES}

1. Kinnear PR, Aspinall PA, Lakowski R. The diabetic eye and colour vision. Trans Ophthalmol Soc UK 1972; 92:69-78.

2. Aspinall PA, Kinnear PR, Duncan LJP, Clarke BF. Prediction of diabetic retinopathy from clinical variables and colour vision data. Diabetes Care 1983;6:144-8.

3. Roy MS, McCulloch C, Hanna AK, Mortimer C. Colour vision in long-standing diabetes mellitus. $\mathrm{Br} \mathrm{J}$ Ophthalmol 1984;68:215-7.

4. Bresnick GH, Condit RS, Palta M, et al. Association of hue discrimination loss and diabetic retinopathy. Arch Ophthalmol 1985;103:1317-24.

5. Daley ML, Watzke RC, Riddle MC. Early loss of bluesensitive colour vision in patients with type 1 diabetes. Diabetes Care 1987;10:777-81.

6. Trick GL, Burde RM, Gordon MO, et al. The relationship between hue discrimination and contrast sensitivity deficits in patients with diabetes mellitus. Ophthalmology 1988;95:693-8.

7. Green FD, Ghafour IM, Allan D, Barrie T, et al. Colour vision of diabetics. $\mathrm{Br} \mathrm{J}$ Ophthalmol 1985; 69:533-6.

8. Maione M, Scoccianti L, Tomba MC, Arsenio L. The regression between FM 100-hue test scores and age in preretinopathic diabetes. In: Verriest G, editor. Colour vision deficiencies: VII. The Hague: W Junk, 1984.

9. Roy MS, Podgor MJ, Collier B, Gunkel RD. Color vision and age in a normal North American population. Graefes Arch Clin Exp Ophthalmol 1991;229:139-44.

10. de Alwis D. The role of automated chromatic contrast sensitivity tests in the management of diabetic retinopathy. MPhil thesis, University of Sussex, 1994.

11. Reffin JP. The design and clinical application of tests of colour vision. DPhil thesis, University of Sussex, 1992.

12. Lutze M, Bresnick GH. Lenses of diabetic patients 'yellow' at an accelerated rate similar to older normals. Invest Ophthalmol Vis Sci 1991;32:194-9.

13. Tregear SJ, Ripley LG, Knowles PJ, Gilday RT, de Alwis DV, Reffin JP. Automated tritan discrimination sensitivity: a new clinical technique for the effective screening of severe diabetic retinopathy. Int J Psychophysiol 1994;16:191-8.

14. Cornsweet TN. The staircase method in psychophysics. Am J Psychol 1962;75:485-91.

15. Sunderraj P, Villada JR, Joyce PW, Watson A. Glare testing in pseudophakes with posterior capsule opacification. Eye 1992;6:411-3.

16. Knighton RW, Slomovic AR, Parrish RK. Glare measurements before and after neodymium-YAG laser posterior capsulotomy. Am J Ophthalmol 1985; 100:708-13.

17. Werner JS, Hardenberg FE. Spectral sensitivity of the pseudophakic eye. Arch Ophthalmol 1983;101:74-6.

18. Pollack A, Leiba H, Bukelman A, Oliver M. Cystoid macular oedema following cataract extraction in patients with diabetes. Br J Ophthalmol 1992;76:221-4.

19. Menchini U, Bandello, F, Brancato R, Camesasca FI Galdini M. Cystoid macular oedema after extracapsular cataract extraction and intraocular lens implantation in diabetic patients without retinopathy. $\mathrm{Br} J$ Ophthalmol 1993;77:208-11.

20. Jampol LM, Kraff MC, Sanders DR, Alexander K, et al. Near-UV radiation from the operating microscope and pseudophakic cystoid macular edema. Arch Ophthalmol 1985;103:28-30.

21. Sebestyen JG. Intraocular lenses and diabetes mellitus. Am J Ophthalmol 1986;101:425-8.

22. Pollack A, Dotan S, Oliver M. Progression of diabetic retinopathy after cataract extraction. Br J Ophthalmol 1991;75:547-51.

23. Pollack A, Dotan S, Oliver M. Course of diabetic retinopathy following cataract surgery. $\mathrm{Br} \mathrm{J}$ Ophthalmol 1991;75:2-8.

24. Dowler JGF, Hykin PG, Lightman SL, Hamilton AM. Visual acuity following extracapsular cataract extraction in diabetes: a meta-analysis. Eye 1995;9:313-7. 